\title{
In situ observation with x-ray for tentative exploration of laser beam welding processes for aluminum-based alloys
}

Cite as: J. Laser Appl. 33, 012026 (2021); doi: 10.2351/7.0000315

Submitted: 30 November 2020 - Accepted: 30 November 2020

Published Online: 28 December 2020

Stephan Börner, ${ }^{7}$ Dirk Dittrich, ${ }^{7}$ Philipp Mohlau, ${ }^{7}$ Christoph Leyens, ${ }^{1,2}$ (iD Francisco García-Moreno, ${ }^{3,4}$ (iD Paul Hans Kamm, ${ }^{3,4}$ (D) Tillmann Robert Neu, ${ }^{3,4}$ (D) and Christian Matthias Schlepütz ${ }^{5}$ (D)

\author{
AFFILIATIONS \\ ${ }^{7}$ Fraunhofer IWS Dresden, Winterbergstrasse 28, 01277 Dresden, Germany \\ ${ }^{2}$ Technische Universität Dresden, 01062 Dresden, Germany \\ ${ }^{3}$ Helmholtz-Zentrum Berlin für Materialien und Energie, Hahn-Meitner-Platz 1, 14109 Berlin, Germany \\ ${ }^{4}$ Technische Universität Berlin, Strasse des 17. Juni 135, 10623 Berlin, Germany \\ ${ }^{5}$ Paul Scherrer Institute, 5232 Villigen, Switzerland
}

Note: Paper published as part of the special topic on Proceedings of the International Congress of Applications of Lasers \& Electro-Optics 2020

\begin{abstract}
In recent years, laser processes have taken an ever-increasing market share in the manufacture of components. The development of new, improved beam sources with corresponding systems technology and the decreasing investment costs of the beam sources are important keys to this success. Particularly, high frequency beam oscillation has great potential in laser beam welding and cutting. The main obstacle for the widespread breakthrough of high frequency (HF) beam oscillation is the still insufficient understanding of the underlying physical mechanisms. Gaining a deeper insight is essential for process optimization. The in situ observation with $\mathrm{x}$ rays enables the visualization and analysis of these highly dynamic processes inside the workpiece. The goal of the performed experiment described in this paper was to in situ analyze the structural evolution of and defect generation in laser welding beads of different aluminum alloys. A fiber laser (max. $600 \mathrm{~W}$, cw output power) including a beam scanner control system for rapid beam guidance was used. Of general interest was the comparison between static and oscillated beam guidance and the effects on the joining procedure. This paper shows the initial results of the analysis of the melt pool behavior and seam formation as well as the formation of seam irregularities during the laser process. In the simplest case, radiographs were taken, i.e., $2 \mathrm{D}$ projections of the $\mathrm{x}$-ray absorption coefficient distribution within a material. Thereby, recordings from 10000 up to $40000 \mathrm{fps}$ could be generated. Furthermore, tomoscopies-the continuous acquisition of tomographic (3D) images, up to 100 tomograms per second-could be generated with proven equipment, whose main components are a high-speed rotation stage and a camera system. The findings will help to get a better understanding of keyhole phenomena as well as effects of turbulent melt flow such as pore formation and guide to solutions for preventing them. Hence, initial results of high frequency beam oscillation processes including melt pool degassing and porosity reduction will be shown and discussed.
\end{abstract}

Key words: laser beam welding, $\mathrm{x}$-ray imaging, high frequency beam oscillation, aluminum, keyhole phenomena, process stabilization, degassing, pore formation, oxide skin

Published under license by Laser Institute of America. https://doi.org/10.2351/7.0000315

\section{INTRODUCTION AND MOTIVATION}

Aluminum alloys have become an indispensable part of aircraft and automobile construction and are one of the keys to lightweight construction. As the proportion of aluminum in vehicles is constantly increasing and the complexity of the components continues to rise, efficient and flexible joining processes become more and more essential. Laser beam welding is capable to meet these challenges. Driven by new developments of optical components and 
decreasing investment costs per kilowatt laser power, the market share of laser beam welding in manufacture of various components is increasing.

Despite higher welding speeds, lower energy input, and thus less distortion compared to conventional joining processes, laser beam welding of aluminum poses great challenges to technologists in different branches. Besides the high thermal conductivity and the low viscosity of the melt, the high reflectivity of the material to laser beam emerges as an additional problem. This results in unstable processes, high porosity, and other seam defects.

In order to be able to evaluate weld seams with regard to their quality and to gain a better understanding of the process itself, different observation tools are available. Camera-based process monitoring is usually used to analyze high-resolution images of the keyhole and the melt pool movement or spatter formation. For the determination of the inner seam quality, mainly different downstream and partly destructive testing methods are applied. For example, $\mathrm{x}$-ray images and metallographic sections can be assessed with regard to pore size and number after welding.

With these classic evaluation tools, characteristic phenomena in laser beam welding of aluminum, especially when comparing static and dynamic beam guidance, can be observed. The high frequency beam oscillation allows reducing spattering and preventing ejections of the melt pool. In addition, the number and size of pores can be reduced to a minimum, even with materials that are difficult or almost impossible to weld, such as aluminum die cast. Overall, the seam formation achieved by using high frequency beam oscillation is much more homogeneous (Fig. 1).

The insufficient understanding of the underlying physical phenomena is a major obstacle to the technology breakthrough. In order to investigate the mechanisms of the stabilizing effect through oscillation and to gain a deeper understanding of the process, in situ x-ray
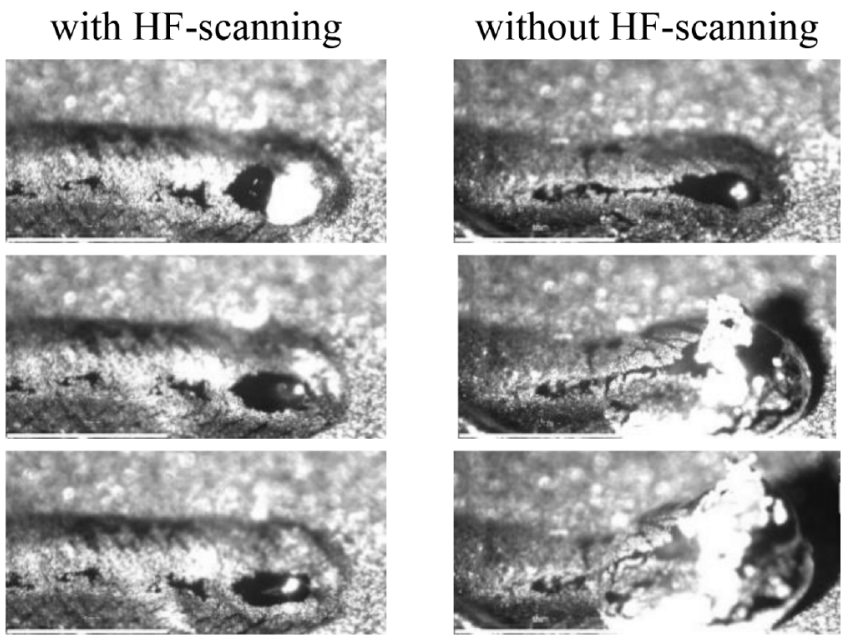

FIG. 1. Comparison of melt pool appearance with high frequency (HF)-scanning (homogeneous process) and static beam (melt pool ejection). Reproduced with permission from Dittrich et al., J. Laser Appl. 29, 022425 (2017). Copyright 2017, AIP Publishing LLC. images were taken. During the welding process, it is possible to observe the keyhole and melt pool movement. Moreover, the pore formation can be traced.

\section{STATE OF THE ART}

Various approaches have been followed to solve the known problems of laser beam welding of aluminum. Selected methods for the stabilization of the welding process will be briefly explained below.

\section{A. High-speed welding}

Peng et $a{ }^{2}{ }^{2}$ found in their studies with tracer particles in AA 6056 during $\mathrm{x}$-ray imaging that process pores are formed specifically on the underside of the capillary. These cannot leave the melt pool before the solidification front reaches them. At comparatively low welding speeds, turbulences occur in the weld pool, which also promote the formation of pores. With increasing welding speeds, the melt pool stabilizes, backflows and vortices decrease, and the porosity can be significantly reduced. At higher welding speeds, the capillary stabilizes due to higher evaporation at the front and thus higher internal pressure, which keeps the capillary open.

Fetzer et l. $^{3}$ were able to improve the seam quality with AA6016 by means of higher welding speeds in the range of 30-75 $\mathrm{m} / \mathrm{min}$ and a laser power of $16 \mathrm{~kW}$. A stable and widened capillary enabled pore-free seems to be produced. In addition, the tendency to hot cracking could be reduced by a lower energy per unit length.

In addition to the high demands placed on the traversing axes of the machine by high welding speeds, very powerful beam sources are necessary to achieve the corresponding welding depths. This increases the investment costs of the weld system.

\section{B. Beam shaping}

Another strategy to improve the laser welding process of aluminum includes the use of adjustable ring mode (ARM) lasers. With these ARM lasers, an individual adjustment of the intensity distribution is possible. The first results of Mikel et al. ${ }^{4}$ and Maina et al. ${ }^{5}$ show a reduction of pores and spatter tendency and a higher surface quality by using an additional ring around the actual laser spot on AA3003 and AA 5022. Nevertheless, this method needs to be further investigated.

\section{Beam oscillation with low frequency}

Fetzer et al. ${ }^{6}$ showed in their $\mathrm{x}$-ray investigations that the pore formation during static welding without oscillation corresponds to a recurring cycle. Excessive evaporation causes the capillary to bulge and finally a bubble to detach. When comparing different forms of oscillations, the stabilizing effect of circular oscillation with frequencies between 100 and $200 \mathrm{~Hz}$ was proven. It has been shown that a bubble can be degassed by passing over it again via the moving capillary. Sinusoidal (longitudinal and lateral) beam oscillation patterns can even promote pore growth.

Wang et al. ${ }^{7}$ also came to the conclusion that the best welding results can be achieved with a circular oscillation pattern. According to Wang et al. ${ }^{7}$ and Hagenlocher et al., ${ }^{8}$ circular beam oscillation can also improve the mechanical properties and hot cracking tendency. 
Recent $\mathrm{x}$-ray investigations with up to $1000 \mathrm{fps}$ by Hagenlocher et al. ${ }^{9}$ show the formation of pores during laser beam welding with disk laser (through-welding) of AA6016 sheets with an intentionally applied oil layer. In this process, rapidly growing gas bubbles appear a few millimeters behind the capillary. The stability of the capillary itself is not affected by uncleaned surfaces. Therefore, it was assumed that process strategies that stabilize the capillary cannot causally avoid the formation of pores.

\section{Laser beam welding of aluminum die cast}

Particularly, aluminum cast alloys are very difficult to weld due to their high porosity in their initial state and the entrapped gases. ${ }^{10}$ Since aluminum die cast is used, for example, as a material for battery housings, media tightness is a decisive factor in joining these materials. To reduce the porosity, in Ref. 11, an electromagnetic system was used to influence the melt. The different electrical conductivities between gases and molten aluminum allow a displacement of the pores to the surface. The main reason for the massive pore formation in aluminum die cast is the hydrogen that remains in the molten metal during solidification due to insufficient degassing. In Ref. 12, this could be reduced by welding in vacuum. Since processing under vacuum is costly, the efficiency of this method is questionable. Dittrich et al. ${ }^{13}$ have developed a process in which high frequency beam oscillation can be used to calm the melt pool. The formation of spatter and pores can be drastically reduced.

\section{APPROACH}

From the classic weld seam quality evaluation tools (high speed-imaging of keyhole or metallographic sections), it is clear that the process stability can be influenced by means of high frequency beam oscillation. Based on the results of Ref. 1, this paper aims to identify the differences between static and dynamic laser beam welding processes. In particular, the stabilizing effect of the high frequency beam oscillation will be investigated in more detail.

In the study by Dittrich et al., ${ }^{1}$ the theory was established that the laser beam gradually slices the material. This theory needs to be verified. In order to increase the understanding of these highly dynamic processes, radioscopies were made in a first step. With the help of these time-resolved $2 \mathrm{D} x$ rays with acquisition rates of up to $40000 \mathrm{fps}$, particularly the keyhole movement and pore formation can be reconstructed. In order to display the welding processes in $3 \mathrm{D}$, tomoscopies were generated.

Tomoscopy is a newly developed procedure for the creation of time-resolved $3 \mathrm{D} x$-ray images. It is a form of tomography that is extended by the time component. By means of a rotating sample table with exact position recognition, $\mathrm{x}$-ray images of the samples can be taken at high image frequencies. The sectional images calculated afterward are combined to 3D images, so-called tomograms. With currently up to 200 tomograms per second, 3D images are created that allow the processes inside the sample to be tracked over time. With this procedure, for example, the formation of metallic foams was investigated by García-Moreno et al. ${ }^{14}$ In this paper, the method is used for the first time for observation of laser beam welding processes.

\section{EXPERIMENTAL SETUP}

The imaging was performed at the TOmographic Microscopy and Coherent rAdiology experimenTs beamline (TOMCAT) of the Paul Scherrer Institute's Swiss Light Source, Villigen, Switzerland. The polychromatic radiation, generated by a superconducting $2.9 \mathrm{~T}$ bending magnet, was filtered with $5 \mathrm{~mm}$ glassy carbon and $325 \mu \mathrm{m} \mathrm{Si}$ to reduce the low radiation energies to keep the heat exposure of the $150 \mu$ m-thick LuAG:Ce scintillator (Crytur, Czech Republic) low. The transmitted radiation of the sample converted into visible light was redirected and enlarged by a mirror system with a high-resolution macroscope (Optique Peter, France) with a fixed magnification of $\times 4 .{ }^{15}$ For this purpose, the GigaFRoST camera system, ${ }^{16}$ which allows high-speed recordings over a very long period (minutes), was used, resulting in an effective pixel size of $2.75 \mu \mathrm{m}$. For the tomoscopy experiments, the sample was rotated at $50 \mathrm{~Hz}$ on a precise rotation stage $^{14}$ and projections were recorded with a repetition rate of $10000 \mathrm{fps}$ over the period of the welding test. In each case, 100 projections taken over a rotation angle of $180^{\circ}$ were filtered using the propagation-based phase retrieval algorithm ${ }^{17}$ and reconstructed with the gridrec algorithm. ${ }^{18}$ The adjusted welding speed of $1 \mathrm{~m} / \mathrm{min}$ resulted in an experiment duration of $565 \mathrm{~ms}$ for a welding circle diameter of $3 \mathrm{~mm}$, which was temporally resolved by 57 tomograms.

The welding tests were carried out with a portable single mode fiber laser with a maximum $\mathrm{cw}$-laser power of $600 \mathrm{~W}$ at a wavelength of $1070 \mathrm{~nm}$. The focus diameter was $33 \mu \mathrm{m}$. A welding head with a galvanometer scanner was used for beam deflection (Fig. 2). For

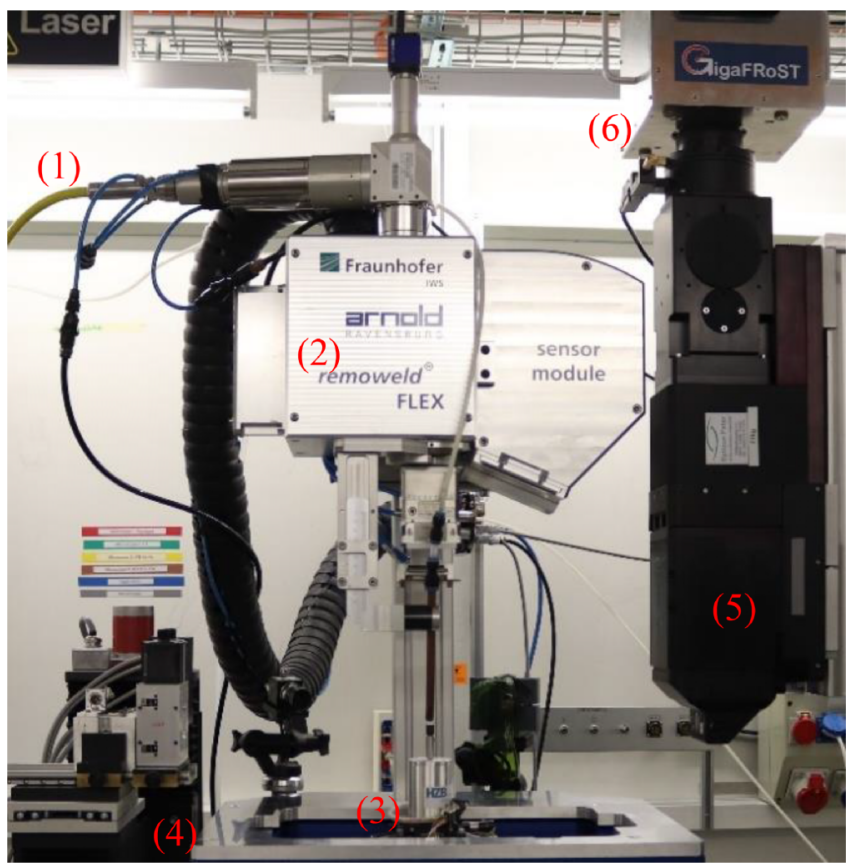

FIG. 2. Experimental setup with laser light cable (1), modular welding head with collimation, focusing unit and integrated $x-y$ scanner (2), rotation stage with sample holder (3), slits/shutter (4), high-resolution macroscope, (5) and GigaFRoST camera (6). 
welding materials that are difficult to join, Fraunhofer IWS Dresden developed the "remoweld ${ }^{\circ}$ FLEX" welding optics, which operates with high frequency beam oscillation and can be equipped with integrated process monitoring and sensor modules. The scanner concept is constantly being improved and currently enables scan frequencies of up to $4 \mathrm{kHz}$ in a working field of $\sim 1.5 \times 1.5 \mathrm{~mm}^{2}{ }^{19}$

To enable a comparison between static laser beam welding and laser beam welding with high frequency beam oscillation, the welds were always carried out with the same laser power $\left(P_{L}=300\right.$ or $\left.400 \mathrm{~W}\right)$ and welding speed $\left(v_{w}=1 \mathrm{~m} / \mathrm{min}\right)$. In the high frequency beam oscillation experiments, the circular scanning pattern with a diameter of $100 \mu \mathrm{m}$ was used. A scanning frequency of $4000 \mathrm{~Hz}$ was chosen.

In addition to the wrought alloys AlMg3 and AlMg4.5Mn0.7, a die cast alloy was also examined in the experiments. The samples were cut or milled from plate material. The following sample dimensions were prepared for the different $\mathrm{x}$-ray methods:

- $8 \mathrm{~mm} \times 5 \mathrm{~mm} \times t$ (with $t=1 ; 2 ; 3 \mathrm{~mm}$ ) cuboids for the radiography experiments

- Cylinders of 5 and $8 \mathrm{~mm}$ diameter and $\sim 5 \mathrm{~mm}$ length to fit into the small graphite crucible used for tomoscopy at high acquisition rates $(\geq 50$ tps $)$

- In order to illustrate a typical combination of aluminum based alloys, a milled wrought alloy pin $(d=3 \mathrm{~mm})$ was inserted into a ring of aluminum die cast $(d=8 \mathrm{~mm})$ for tomoscopy experiments.

In the following, selected phenomena of the measurement campaign shall be presented. Notably, these fundamental studies were performed using yet not optimized process parameters.

\section{RESULTS}

\section{A. Bead on plate welding in wrought aluminum}

In a first step, welds were made in AlMg3 as a reference. Irregularities and keyhole movement were analyzed using high-

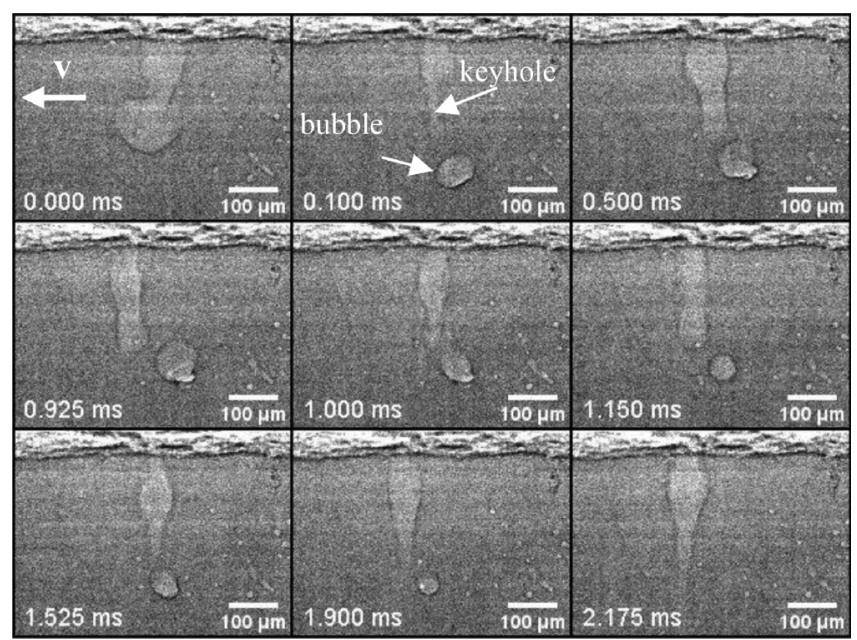

FIG. 3. X-ray imaging of the formation and gradual degassing of a bubble by the oscillating keyhole in AIMg3 during laser welding with high frequency beam oscillation. speed 2D-x-ray imaging with $40000 \mathrm{fps}$. Figure 3 shows the process of formation and degassing of a gas bubble in the melt during welding with high frequency beam oscillation.

The first image in the sequence shows the formation of a bubble starting from the tip of the keyhole. After $0.1 \mathrm{~ms}$, the bubble settles at the edge of the melting line and starts to grow from there in the feed direction. By passing the bubble again through with the oscillation beam, a gradual degassing can begin after $1.0 \mathrm{~ms}$. The bubble is pulled along by the moving keyhole and decreases in volume until it finally disappears after $2.175 \mathrm{~ms}$. The effect of stepwise degassing via the oscillating keyhole could thus be demonstrated for the first time also for high scanning frequencies.

\section{B. Bead on plate welding in aluminum die cast}

\section{Static laser beam welding}

Aluminum die cast alloys are known to be difficult to weld. Particularly, the entrapped gases are problematic. The sequence in Fig. 4 shows parts of an x-ray video with $10000 \mathrm{fps}$ of static laser welding (without oscillation) of an aluminum die cast alloy. Massive pore formation is obvious.

The first image is intended to visualize the piercing of a gas inclusion. The resulting bubble grows very strongly over the next $4 \mathrm{~ms}$ until it reaches the surface of the sample and finally collapses in a flash. After $5 \mathrm{~ms}$, the keyhole hits a gas inclusion again. The second bubble does not grow so strongly and can therefore degas via the keyhole in the next $10 \mathrm{~ms}$. Nevertheless, the sequence shows that the process is very unstable, which is again visible in a bubble formation from the tip of the keyhole.

\section{Laser welding with high frequency beam oscillation}

The sequence of images in Fig. 5 shows the formation of bubbles and the degassing via the moving keyhole. In the $\mathrm{x}$-ray video, the formation of bubbles starting from the surface of the

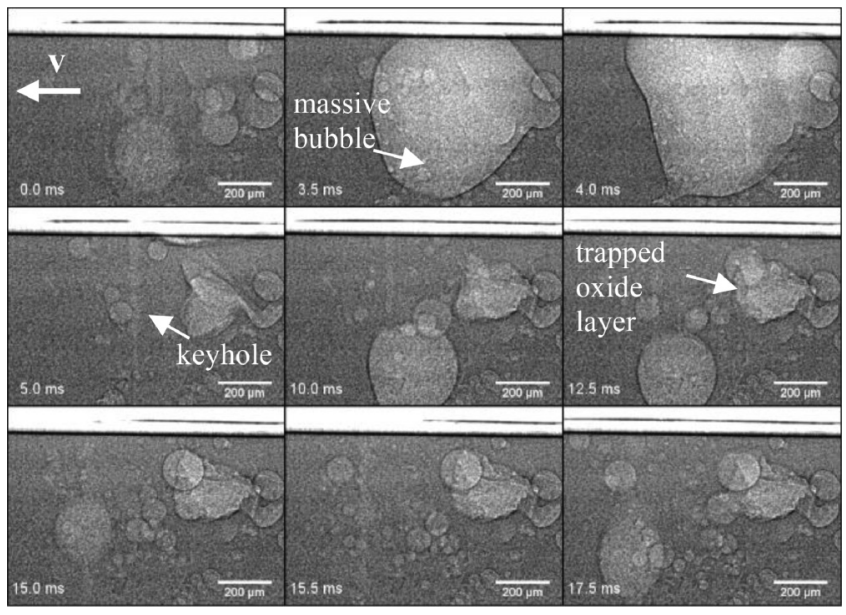

FIG. 4. X-ray imaging of the pore formation in aluminum die cast illustrating the collapse of a massive bubble during static laser beam welding. 

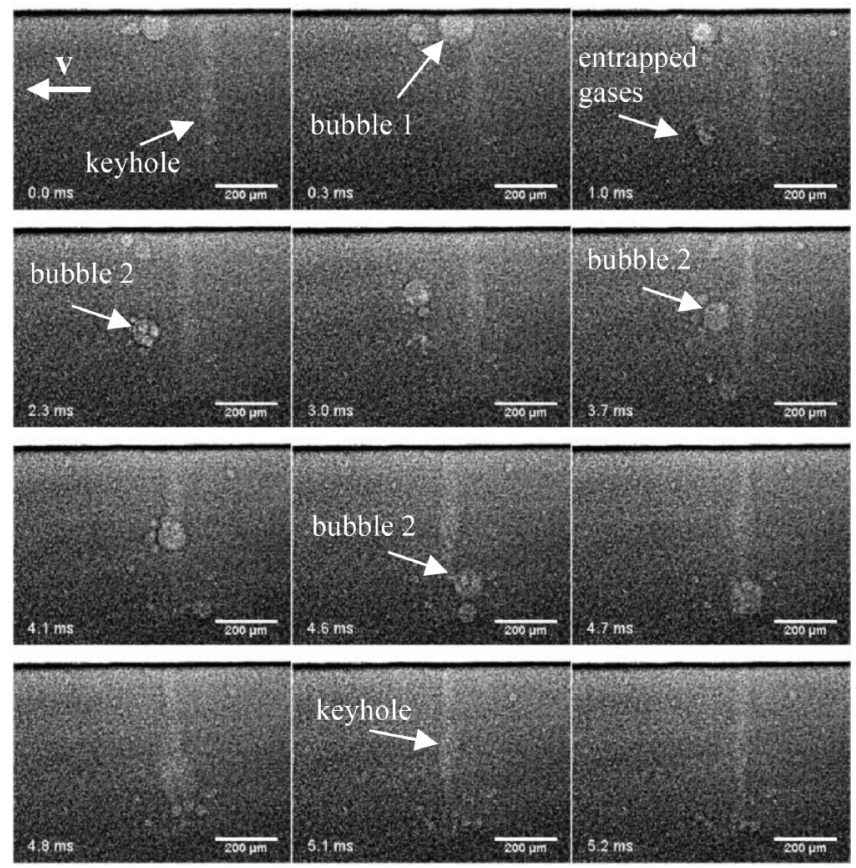

FIG. 5. X-ray imaging of degassing of entrapped gases in aluminum die cast during laser beam welding with high frequency beam oscillation.

melt pool in front of the keyhole can be observed. Within the first millisecond, a bubble (bubble 1) can be degassed via the keyhole.

In addition, after the first millisecond, it becomes apparent that the melt front encounters entrapped gases. The gradual slicing of the entrapped gases produces many small bubbles. These combine after $2.3 \mathrm{~ms}$ to form a larger one (bubble 2 ). The rapidly oscillating keyhole creates strong flows, which push bubble 2 behind the keyhole (after $4.6 \mathrm{~ms}$ ). A tenth of a millisecond later, the keyhole reaches the bubble, which can completely be degassed via the vapor capillary.

The initial state of the material has a great influence on the welding result. In order to minimize this influence, in addition to the purely static and purely dynamic tests, samples were generated by changing from static to dynamic beam guidance. In Fig. 6, a stabilizing effect of the high frequency beam oscillation is shown.

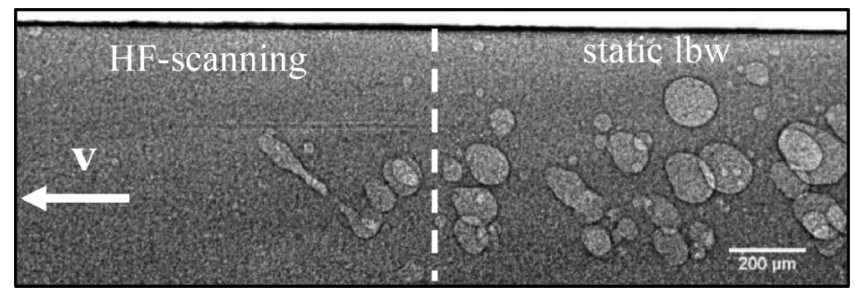

FIG. 6. $\mathrm{X}$ ray of the final state after welding in aluminum die cast-change from static laser beam welding (right) to high frequency beam oscillation (left) during the welding process.
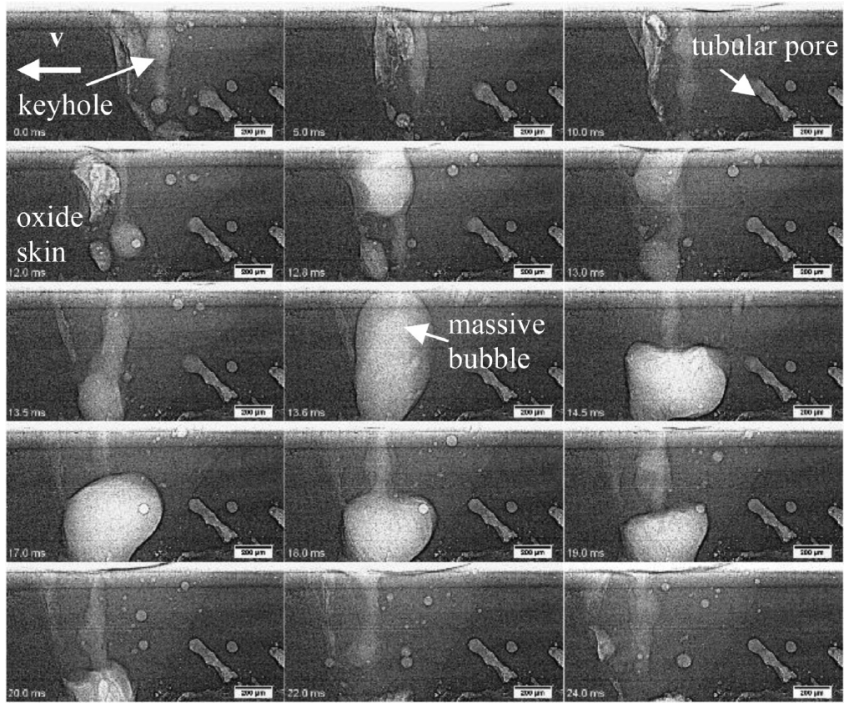

FIG. 7. X-ray imaging of laser beam welding with high frequency beam oscillation of two aluminum sheets (butt weld)-formation of tubular pores and keyhole interaction with oxide skin.

Despite massive pore formation in static laser beam welding, the process stabilizes after switching to dynamic beam guidance.

\section{Joining of two aluminum sheets}

Interesting phenomena could be observed during laser beam welding of two aluminum sheets in butt weld. Due to the uncleaned surface of the samples, strong pore formation also occurred in the welding process with high frequency beam oscillation (Fig. 7). In the first $10 \mathrm{~ms}$ of the sequence, the growth of a tubular pore perpendicular to the solidification front behind the keyhole is shown.

In front of the melt pool, a type of oxide skin appears. Due to the higher melting temperature compared to the aluminum alloy, it is visible in the molten bath as a solid component. These oxide layers have already been detected in thin, liquid aluminum alloy films. ${ }^{20}$ After $12 \mathrm{~ms}$, the keyhole reaches the oxide layer. In the next millisecond, the keyhole interacts with the oxide skin and a bubble on the melt front. This results in an explosive formation of a large bubble (up to $17 \mathrm{~ms}$ ). By repeatedly passing the keyhole over the bubble, it can gradually degas over the next milliseconds via the vapor capillary. After $24 \mathrm{~ms}$, the process has completely stabilized again.

This sequence shows that it is not possible to create completely pore-free seams under all circumstances. But the process can be stabilized again after a strong irregularity by high frequency beam oscillation.

\section{Tomoscopy experiments}

In addition to the radiographs (2D), tomoscopies were taken. Figures 8 and 9 show the comparison between static laser beam 


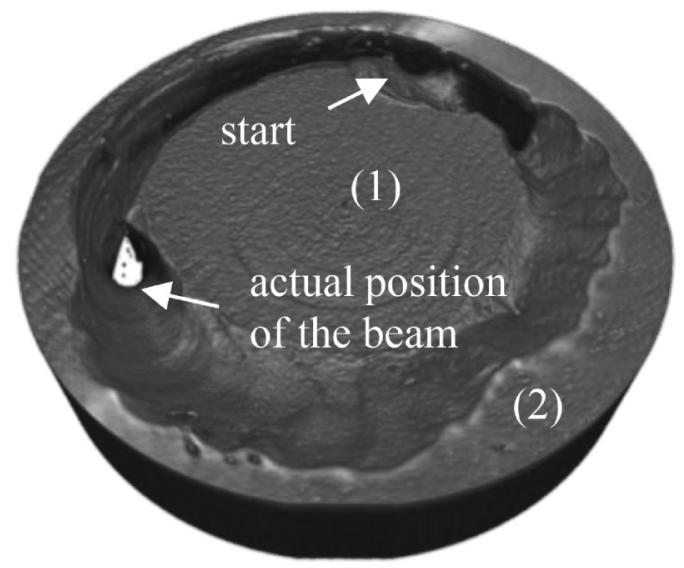

FIG. 8. Section of a tomoscopy during static laser beam welding with strong weld seam arching and ejections-joining of wrought alloy pin (1) and aluminum die cast ring (2).

welding and high frequency beam oscillation for joining of a milled wrought alloy pin and a ring of aluminum die cast. The 3D images display a section after about three quarters of the seam length.

For tomoscopies, a circular weld seam contour with a diameter of $3 \mathrm{~mm}$ (diameter of the milled wrought alloy pin) was created using beam deflection optics. Superimposed on the rotation of the sample during tomography, the laser beam was moved at the same speed plus the welding speed. This ensured the relative movement between the sample and the laser beam. It should be pointed out again that these experiments were performed under nonoptimized process conditions.

Nevertheless, typical phenomena already known from the literature are shown. ${ }^{1,13}$ In the static laser beam welding in Fig. 8, two

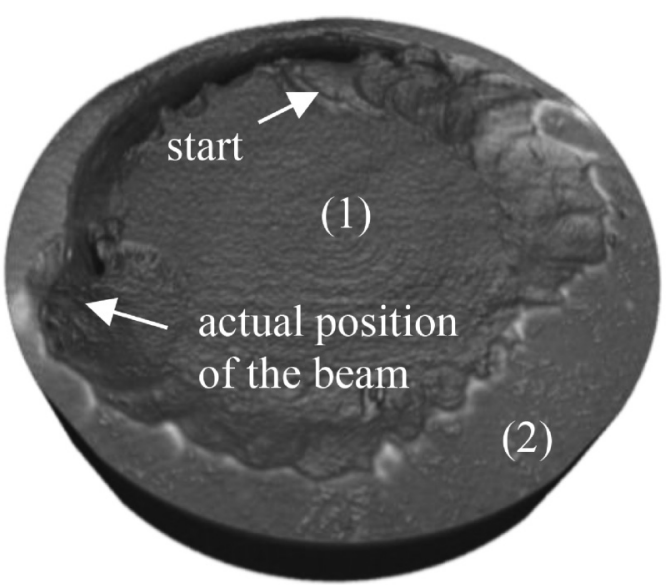

FIG. 9. Section of a tomoscopy during laser beam welding with high frequency beam oscillation with homogenous weld seam-joining of wrought alloy pin (1) and aluminum die cast ring (2). large craters become visible immediately after the start of the process. In addition, a clear seam arch is visible over the entire seam. In comparison, high frequency beam oscillation can produce a more homogeneous seam appearance (Fig. 9).

Tentative evaluations of $3 \mathrm{D}$ sections through the material show differences between static and dynamic beam guidance in terms of pore size and number. In static laser beam welding, larger and more outwardly open pores remain. With high frequency beam oscillation, smaller closed porous gas inclusions can be identified. These smaller closed pores are less critical with regard to media tightness and mechanical properties.

\section{CONCLUSION}

The presented results allow further insight into the known phenomena occurring during laser beam welding of different aluminum alloys. Using high-speed $\mathrm{x}$-ray imaging, the effect of stepwise degassing by the oscillating keyhole could be demonstrated for the first time even at high scanning frequencies. When welding aluminum die cast, the stabilizing effect of the high frequency beam oscillation is again evident. In addition, the laser welding process was visualized with time-resolved 3D $\mathrm{x}$-ray images using an already proven method. Obviously, the 2D oscillation has an influence on the melt pool movement and the formation of seam defects. However, it is still necessary to link the observed effects with the process in order to optimize the welding parameters. Further studies on oscillation in 3D space and the transferability of the results to other materials such as copper alloys would be interesting.

\section{ACKNOWLEDGMENTS}

The authors acknowledge the Paul Scherrer Institut, Villigen, Switzerland, for provision of synchrotron radiation beamtime at the TOMCAT beamline X02DA of the SLS.

\section{REFERENCES}

${ }^{1}$ D. Dittrich, A. Jahn, J. Standfuss, and E. Beyer, "Laser beam welding of atmosphere aluminium die cast material using high frequency beam oscillation and brilliant beam sources,” J. Laser Appl. 29, 022425 (2017).

2J. Peng, L. Li, S. Lin, F. Zhang, Q. Pan, and S. Katayama, "High speed x-ray transmission and numerical study of melt flows inside the molten pool during laser welding of aluminum alloy,” Math. Probl. Eng. 2016, 1409872 (2016).

${ }^{3}$ F. Fetzer, C. Hagenlocher, and R. Weber, "High power, high speed, high quality - advantages of laser beam welding of aluminum sheets at $16 \mathrm{~kW}$ of laser power and feed rates up to $50 \mathrm{~m} / \mathrm{min}$," Laser Tech. J. 15, 28-31 (2018).

${ }^{4}$ T. Mikel, D. Langenkamp, and S. Ream, in Proceedings of the International Congress on Applications of Lasers \& Electro-Optics-Macro 802, Orlando, FL, 7-10 October 2019 (Laser Institute of America (LIA), Orlando, 2019).

${ }^{\mathbf{5}}$ M. R. Maina, Y. Okamoto, A. Okada, M. Närhi, J. Kangastupa, and J. Vihinen, "High surface quality welding of aluminum using adjustable ring-mode fiber laser," J. Mater. Process. Technol. 258, 180-188 (2018).

${ }^{6}$ F. Fetzer, M. Sommer, R. Weber, J.-P. Weberpals, and T. Graf, "Reduction of pores by means of laser beam oscillation during remote welding of AlMgSi," Opt. Lasers Eng. 108, 68-77 (2018).

${ }^{7}$ L. Wang, M. Gao, C. Zhang, and X. Zeng, "Effect of beam oscillating pattern on weld characterization of laser welding of AA6061-T6 aluminum alloy," Mater. Des. 108, 707-717 (2016). 
${ }^{8}$ C. Hagenlocher, M. Sommer, F. Fetzer, R. Weber, and T. Graf, "Optimization of the solidification conditions by means of beam oscillation during laser beam welding of aluminum," Mater. Des. 160, 1178-1185 (2018).

${ }^{9} \mathrm{C}$. Hagenlocher, J. Lind, R. Weber, and T. Graf, "High-speed x-ray investigation of pore formation during full penetration laser beam welding of AA6016 aluminum sheets contaminated with lubricants," Appl. Sci. 10, 2077 (2020).

${ }^{10}$ A. I. Taub and A. A. Luo, "Advanced lightweight materials and manufacturing processes for automotive applications," MRS Bull. 40, 1045-1054 (2015).

${ }^{11}$ A. Fritzsche, K. Hilgenberg, and M. Rethmeier, "Influence of welding parameters on electromagnetic supported degassing of die-casted and wrought aluminum," J. Laser Appl. 32, 022031 (2020).

${ }^{12}$ F. Teichmann, S. Müller, and K. Dilger, "On the occurrence of weld bead porosity during laser vacuum welding of high pressure aluminium die castings," Proc. CIRP 74, 438-441 (2018).

${ }^{13}$ D. Dittrich, J. Standfuss, and A. Jahn, "Neuartiges verfahren zum druckdichten laserstrahl-schweißen von aluminium aus atmosphären-druckguss," Gießerei 104(8), 56-61 (2017).

${ }^{14}$ F. García-Moreno, P. H. Kamm, T. R. Neu, F. Bülk, R. Mokso, C. M. Schlepütz, M. Stampanoni, and J. Banhart, "Using $\mathrm{x}$-ray tomoscopy to explore the dynamics of foaming metal," Nat. Commun. 10, 1-9 (2019).

${ }^{15}$ M. Bührer, M. Stampanoni, X. Rochet, F. Büchi, J. Eller, and F. Marone, "High-numerical-aperture macroscope optics for time-resolved experiments," J. Synchrotron Radiat. 26, 1161-1172 (2019).

${ }^{16}$ R. Mokso, C. M. Schlepütz, G. Theidel, H. Billich, E. Schmid, T. Celcer, G. Mikuljan, L. Sala, F. Marone, N. Schlumpf, and M. Stampanoni, "GigaFRoST:
The gigabit fast readout system for tomography," J. Synchrotron Radiat. 24, 1250-1259 (2017).

${ }^{17}$ D. Paganin, S. C. Mayo, T. E. Gureyev, P. R. Miller, and S. W. Wilkins, "Simultaneous phase and amplitude extraction from a single defocused image of a homogeneous object," J. Microsc. 206, 33-40 (2002).

${ }^{18} \mathrm{~F}$. Marone and M. Stampanoni, "Regridding reconstruction algorithm for realtime tomographic imaging," J. Synchrotron Radiat. 19, 1029-1037 (2012).

${ }^{19}$ M. Kraetzsch, J. Standfuss, A. Klotzbach, J. Kaspar, and B. Brenner, "Laser beam welding with high-frequency beam oscillation: welding of dissimilar materials with brilliant fiber lasers," Phys. Procedia 12, 142-149 (2011).

${ }^{20}$ K. Heim, F. García-Moreno, G. S. Vinod Kumar, A. Rack, and J. Banhart, "The rupture of a single liquid aluminium alloy film," Soft Matter 10, $4711-4716(2014)$

\section{Meet the Author}

Dipl.-Ing. (IWE) Stephan Boerner studied mechanical engineering at TU Dresden. He works as a research assistant in the "Laser Beam Welding" group at Fraunhofer IWS Dresden. His areas of work include the development of new laser beam welding technologies, for example, laser welding with high frequency beam oscillation or laser beam welding with green and blue lasers. The materials being considered include aluminum- and copper-based alloys for the application fields of automotive or battery technology. 